\title{
Mebeverine Hydrochloride Loaded Chitosan Microspheres as Potential Treatment Targeting Irritable Bowel Syndrome: Box-Behnken Design Optimization
}

\author{
Azza Ali Hasan 1, Rasha Mohamed Samir', Samir Sayed Abu-Zaid', Amr Selim Abu Lila2,* \\ 'Department of Pharmaceutics and Industrial Pharmacy, Faculty of Pharmacy, Zigzag University, Zagazig, EGYPT. \\ 2Department of Pharmaceutics, College of Pharmacy, Hail University, Hail, SAUDI ARABIA.
}

\begin{abstract}
Objective: Mebeverine hydrochloride is an antispasmodic agent that has a direct musculotropic action on the smooth muscles of the gastrointestinal tract; especially the colon. Therefore, the current study aimed at formulating and optimizing colon targeted mebeverine hydrochloride microspheres for treatment of chronic gastrointestinal disorder. Methods: Mebeverine hydrochloride-loaded chitosan microspheres were formulated adopting emulsion cross-linking method using glutaraldehyde as a cross linking agent. A $3^{3}$ Box Behnken design was utilized in formulating the microspheres and investigating the effect of different formulation factors such as drug: polymer ratio $\left(X_{1}\right)$, stirring speed $\left(X_{2}\right)$ and the surfactant concentration $\left(X_{3}\right)$ on particle size $\left(Y_{1}\right)$, the entrapment efficiency percentage $\left(Y_{2}\right)$ and the cumulative release percentage of mebeverine hydrochloride after $8 \mathrm{~h}\left(\mathrm{Y}_{3}\right)$. Result: The particle size and entrapment efficiency were significantly affected by tested formulation parameters. The release of mebeverine hydrochloride from optimized formula was $\mathrm{pH}$ dependent. In simulated gastric fluid, less than $10 \%$ of entrapped mebeverine hydrochloride was released, while, a relatively high amount of the drug ( $>65 \%$ ) was released in simulated colonic fluid ( $\mathrm{pH}$ 7.4). The in vivo pharmacokinetic study revealed that the optimized formula of microspheres exhibited increased
\end{abstract}

oral absorption of mebeverine hydrochloride, compared to free drug ( $C_{\max } 168.51 \pm 20.05 \mathrm{ng} / \mathrm{ml}$ vs. $126.45 \pm 29.46 \mathrm{ng} / \mathrm{ml}$, respectively). In addition, the optimized formula exerted a remarkably higher systemic bioavailability, compared to the free drug. Conclusion: These results underscore the applicability of cross-linked chitosan microspheres as a promising carrier for colon targeted delivery of mebeverine hydrochloride for treating diseases associated with the colon such as irritable bowel syndrome.

Key words: Box-Behnken design, Chitosan, Irritable bowel syndrome, Mebeverine hydrochloride, Microspheres.

\section{Correspondence}

Dr. Amr S. Abu Lila,

Associate Professor, Department Department of Pharmaceutics, College of Pharmacy, Hail University, Hail-81442, SAUDI ARABIA.

Phone: +966-565434262

Email: amr_selim78@yahoo.com;

ORCID: http://orcid.org/0000-0001-7385-868X

DOI: 10.5330/ijpi.2020.3.58

\section{INTRODUCTION}

Irritable bowel syndrome (IBS), a chronic gastrointestinal disorder, is characterized by abdominal pain and an erratic bowel habit. ${ }^{1,2}$ Mebeverine hydrochloride $(\mathrm{MBH})$ is an antispasmodic agent that has a direct musculotropic action on the smooth muscles of the gastrointestinal tract; especially the colon. ${ }^{3}$ For many years, $\mathrm{MBH}$ has been considered the drug of choice for the management of IBS. ${ }^{4,5}$ Nevertheless, following oral administration, $\mathrm{MBH}$ is rapidly absorbed from the upper part of gastrointestinal tract and undergoes extensive hepatic metabolism. ${ }^{6}$ This adversely hinders the delivery of MHB to the site of action; colon, in appropriate concentrations. Accordingly, development of drug delivery systems that are capable of delivering $\mathrm{MBH}$ to the diseased organ (colon) in adequate concentrations is urgently needed in order to enhance the overall therapeutic efficacy along with reducing the incidence of adverse side effects.

Recently, colon targeted drug delivery systems have gained enormous attention as means for delivering drugs specifically into the colon. ${ }^{7-9}$ Targeting of drugs to colon is valuable approach for treating diseases associated with the colon such as colorectal cancer, ulcerative colitis, Crohn's disease, amebiosis, inflammatory bowel disease and irritable bowel syndrome. ${ }^{10,11}$ Nevertheless, for successful targeted drug delivery to the colon, the delivery vehicle should protect the drug from degradation, release and absorption in stomach and small intestine and should allow the selective/controlled release in the proximal colon. This can be accomplished by the use of well-designed delivery vehicles that can shield the drug during its transit to the colon.

Polymeric micro-particles represent one of the promising delivery vehicles that have been recognized for their potential as therapeutic carriers to the colon. ${ }^{12,13}$ They can be prepared using different kinds of polymers. Among them, naturally occurring biodegradable polymers, especially polysaccharides, have been extensively explored for their potential in colon-specific drug delivery. ${ }^{14,15}$ Polysaccharides, such as chitosan, pectin, inulin, dextran and guar gum, show the potential to be retained intact in the environment of the stomach and small intestine, while being degraded by polysaccharidases upon arrival in the colon. Chitosan is one of the non-toxic biodegradable polysaccharide that is obtained from the alkaline deactivation of chitin. ${ }^{16}$ Chitosan shows a propensity to dissolve in acidic $\mathrm{pH}$ of the stomach but get swollen in the intestinal $\mathrm{pH}$. This gelling property retards drug release from the dosage form, making it more susceptible to degradation in the colon. ${ }^{17,18}$ Consequently, chitosan serves as an effective polymer for the preparation of colon-specific drug delivery systems.

The aim of the present study was, therefore, to formulate and optimize chitosan microspheres loaded with $\mathrm{MBH}$ for colon-specific drug targeting using a 3-factor, 3-level Box Behnken design. In addition, the in vivo fate of the optimized $\mathrm{MBH}$ chitosan microspheres was evaluated in rabbits following oral administration. 


\section{MATERIALS AND METHODS}

\section{Materials}

Mebeverine hydrochloride (MBH) was generously supplied by EPICO (10 $0^{\text {th }}$ of Ramadan city, Egypt). Chitosan low molecular weight (MW 10031), was purchased from Sigma Aldrich. Hydrochloric acid, light liquid paraffin, span80, glutaraldehyde and glacial acetic acid were supplied from El-Nasr Pharmaceutical Chemical Company (Cairo, Egypt). Other chemicals and materials were of analytical grade.

\section{Preparation of mebeverine hydrochloride-loaded chitosan microspheres}

Chitosan microspheres were formulated using the emulsion cross-linking method. ${ }^{19}$ Briefly, different amounts of chitosan and a definite weight of $\mathrm{MBH}$ (100mg) were dissolved in $20 \mathrm{ml}$ of $1 \% \mathrm{v} / \mathrm{v}$ aqueous acetic acid solution. The resulting drug-polymer dispersion was emulsified into an external phase of light liquid paraffin containing different concentrations of span 80. After $30 \mathrm{~min}, 1.5 \mathrm{ml}$ of the glutaraldehyde $(1.25 \%)$ was added and further stirring was continued for $3 \mathrm{~h}$ for cross-linking and stabilization. The formed microspheres were filtered, washed repeatedly with petroleum ether for removing residual liquid paraffin and then dried in hot air oven at $50^{\circ} \mathrm{C}$.

\section{$3^{3}$ level Box Behnken Experimental Design}

A 3-factor, 3-level Box-Behnken design (Statgraphics Centurion version 18 software; Stat Point Technologies Inc., VA, USA) was adopted for optimizing chitosan microspheres of $\mathrm{MBH}$ and to explore the effect of different formulation variables, namely; drug: polymer ratio $\left(\mathrm{X}_{1}\right)$, stirring speed $\left(\mathrm{X}_{2}\right)$ and surfactant concentration $\left(\mathrm{X}_{3}\right)$ on product characteristics, namely; particle size $\left(\mathrm{Y}_{1}\right), \%$ entrapment efficiency $\left(\mathrm{Y}_{2}\right)$ and $\%$ cumulative drug release at $8 \mathrm{~h}\left(\mathrm{Y}_{3}\right)$. A total of fifteen runs were prepared (Table 1).

\section{Physicochemical and morphological characterization of microspheres}

\section{Scanning Electron Microscopy}

Scanning Electron Microscope (SEM, JEOL JSM-5400LV Jeol, Tokyo, Japan) was used to examine the shape and surface morphology of the prepared microspheres.

\section{Particle size analysis}

The average particle size of the prepared microspheres was analyzed using dynamic light scattering (Zetasizer Nano ZS, Malvern, United Kingdom). Suspensions of microspheres in distilled water were used for the measurement. All measurements were conducted in triplicate at $25^{\circ} \mathrm{C}$.

\section{Entrapment efficiency}

Accurately weighed amount (50 mg) of $\mathrm{MBH}$ microspheres was crushed and dispersed in $20 \mathrm{ml}$ phosphate buffer $\mathrm{pH}$ 7.4. The dispersion was continuously agitated on a shaker at $37^{\circ} \mathrm{C}$ for $24 \mathrm{~h}$. The dispersion was then filtered and drug content of the filtrate was determined spectrophotometrically at $\lambda_{\max }$ of $263 \mathrm{~nm}$. The percentage drug entrapment efficiency (\% EE) was estimated using the following formula:

$$
\% \mathrm{EE}=\text { Actual drug content/Theoretical drug content } \times 100
$$

\section{Percentage yield}

The dried microspheres were accurately collected and weighted to obtain the yield of the prepared microspheres. The percentage yield was computed using the following formula:

$$
\begin{aligned}
\% \text { Yield }= & (\text { Actual weight of microspheres } / \\
& \text { Total weight of drug and polymer }) \times 100
\end{aligned}
$$

\section{In vitro release study}

In vitro release of $\mathrm{MBH}$ from chitosan microspheres was conducted in simulated gastric fluid (SGF) and simulated intestinal fluid (SIF) for 2 and $22 \mathrm{hrs}$, respectively, at $37 \pm 1^{\circ} \mathrm{C}$. Both SGF and SIF were prepared as per "British Pharmacopeia 2014" without the addition of digestive enzymes. Chitosan microspheres containing $\mathrm{MBH}$ equivalent to $3 \mathrm{mg}$ were accurately weighed, filled into dialysis bags and suspended in $100 \mathrm{ml}$ dissolution medium. Release studies were carried out in SGF ( $\mathrm{pH} 1.2$ ) for $2 \mathrm{~h}$ followed by SIF (pH 6.8 and 7.4) for $3 \mathrm{~h}$ and $19 \mathrm{~h}$, respectively. Samples of $3 \mathrm{ml}$ were withdrawn at different time intervals $(1,2,3,4,5$, 6,8 , and $24 \mathrm{~h}$ ) and replaced with an equal volume of fresh medium to maintain a constant volume. The drug concentration in each aliquot was analyzed spectrophotometrically at $\lambda_{\max }$ of $263 \mathrm{~nm}$.

\section{Pharmacokinetic study of optimized MBH-loaded chitosan microsphere}

Male albino rabbits (weighing 2 to $2.25 \mathrm{~kg}$ ) were randomly categorized into three groups $(n=4)$. The first group received an oral capsule containing free drug. The second group received the optimized chitosan microsphere formula (FO). MBH dose was $20 \mathrm{mg} / \mathrm{kg}$. The third group received saline instead of $\mathrm{MBH}$ and served as control. All animal experiments were approved by the Institutional Animal Ethics Committee, Faculty of Pharmacy, Zagazig University, Egypt (approval number: $\mathrm{ZU}$-IACUC/3/F/45/2019). At predetermined time points $(0.5,1,2,3$, $4,6,8$ and 24 h post-dose), blood samples $(500 \mu \mathrm{l})$ were collected into heparinized tubes. The plasma fraction was obtained by centrifuging blood samples at $4000 \mathrm{rpm}$ and $4^{\circ} \mathrm{C}$ for $10 \mathrm{~min}$ and then stored at $-20^{\circ} \mathrm{C}$ until analysis. Drug concentration in each plasma sample was quantified by HPLC using a mobile phase consisted of a mixture of $50 \mathrm{mM} \mathrm{KH}_{2} \mathrm{PO}_{4}$, acetonitrile and tetrahydrofuran (THF) (63:35:2\%; v/v/v) and equipped with a UV-VIS detector set at a wavelength of $263 \mathrm{~nm}$. Pharmacokinetic parameters $\left(\mathrm{C}_{\max }, \mathrm{t}_{\max }, \mathrm{K}_{\mathrm{el}}, \mathrm{AUC}_{0-24 \mathrm{~h}}\right.$ and $\left.\mathrm{MRT}\right)$ were estimated from the individual plasma concentrations versus time profiles using the

Table 1: Composition of the formulated batches of MBH microspheres and the obtained responses.

\begin{tabular}{ccccccc}
\hline Run & $\mathrm{X}_{1}$ & $\mathrm{X}_{2}$ & $\mathrm{X}_{3}$ & $\mathrm{Y}_{1}$ & $\mathrm{Y}_{2}$ & $\mathrm{Y}_{3}$ \\
\hline FC1 & $1: 4$ & 1000 & 1.5 & $39 \pm 1.0$ & $11.66 \pm 0.19$ & $100 \pm 0.68$ \\
FC2 & $1: 4$ & 1600 & 1.5 & $32 \pm 0.45$ & $12.85 \pm 0.33$ & $100 \pm 5.30$ \\
FC3 & $1: 8$ & 1000 & 1.5 & $36.4 \pm 1.15$ & $36.15 \pm 1.41$ & $68.31 \pm 1.32$ \\
FC4 & $1: 8$ & 1600 & 1.5 & $40.7 \pm 1.53$ & $48.07 \pm 1.72$ & $60.16 \pm 1.75$ \\
FC5 & $1: 4$ & 1300 & 1 & $33 \pm 1.0$ & $17.5 \pm 0.07$ & $100 \pm 0.22$ \\
FC6 & $1: 4$ & 1300 & 2 & $38.6 \pm 0.51$ & $11.88 \pm 0.42$ & $100 \pm 3.23$ \\
FC7 & $1: 8$ & 1300 & 1 & $41.3 \pm 0.57$ & $47.16 \pm 1.15$ & $57.36 \pm 1.19$ \\
FC8 & $1: 8$ & 1300 & 2 & $46.4 \pm 1.13$ & $33.84 \pm 1.32$ & $59.94 \pm 0.89$ \\
FC9 & $1: 6$ & 1000 & 1 & $40.2 \pm 1.53$ & $23.63 \pm 0.7$ & $100 \pm 2.40$ \\
FC10 & $1: 6$ & 1000 & 2 & $42 \pm 0.57$ & $30.75 \pm 2.84$ & $100 \pm 0.03$ \\
FC11 & $1: 6$ & 1600 & 1 & $34 \pm 1.0$ & $35.66 \pm 0.44$ & $100 \pm 3.40$ \\
FC12 & $1: 6$ & 1600 & 2 & $35.7 \pm 1.43$ & $31.7 \pm 2.12$ & $90.4 \pm 4.80$ \\
FC13 & $1: 6$ & 1300 & 1.5 & $40.7 \pm 3.05$ & $18.87 \pm 2.06$ & $100 \pm 3.19$ \\
FC14 & $1: 6$ & 1300 & 1.5 & $43.65 \pm 1.31$ & $20.18 \pm 1.23$ & $100 \pm 0.97$ \\
FC15 & $1: 6$ & 1300 & 1.5 & $39.85 \pm 2.33$ & $18.45 \pm 0.76$ & $100 \pm 2.09$ \\
\hline
\end{tabular}

Data are represented as mean $\pm \mathrm{SD}$ 
pharmacokinetic software PK solver and the relative bioavailability was computed using the following equation:

Relative bioavailability $(\%)=\left(\mathrm{AUC}_{0-24 \text { (test formulation) }} / \mathrm{AUC}_{0-24 \text { (pure drug) }} \times 100\right.$.

\section{Statistical analysis}

Student's $t$-test and one-way ANOVA was adopted to assess the significance of the difference between different formulationsusing Graph-Pad Prism versions 5.02. Values were represented as the mean \pm SD.

\section{RESULTS}

\section{Effect of formulation variables on physicochemical characteristics of $\mathrm{MBH}$-loaded microspheres}

Mebeverine hydrochloride (MBH)-loaded chitosan microspheres were formulated and optimized by the three-factor, three-level Box-Behnken design (BBD). The quantitative effects of the independent variables $\left(\mathrm{X}_{1}, \mathrm{X}_{2}\right.$ and $\left.\mathrm{X}_{3}\right)$ on the dependent variables $\left(\mathrm{Y}_{1}, \mathrm{Y}_{2}\right.$ and $\left.\mathrm{Y}_{3}\right)$ were fitted into regression analysis and second-order polynomial equations were obtained to explain the mathematical relationships between the dependent and independent variables (equations 1-3).

$\mathrm{Y}_{1}=-1.3625-0.758 \mathrm{X}_{1}+0.056 \mathrm{X}_{2}+8.2677 \mathrm{X}_{3}-0.316 \mathrm{X}_{1}^{2}+0.005$

$\mathrm{X}_{1} \mathrm{X}_{2}-0.125 \mathrm{X}_{1} \mathrm{X}_{3}-0.00003 \mathrm{X}_{2}^{2}-0.0002 \mathrm{X}_{2} \mathrm{X}_{3}-1.25 \mathrm{X}_{3}^{2}$

$\mathrm{Y}_{2}=128.52-3.73 \mathrm{X}_{1}-0.145 \mathrm{X}_{2}-38.473 \mathrm{X}_{3}+0.647 \mathrm{X}_{1}^{2}+0.004 \mathrm{X}_{1} \mathrm{X}_{2}-$ $1.925 \mathrm{X}_{1} \mathrm{X}_{3}+0.00006 \mathrm{X}_{2}^{2}-0.018 \mathrm{X}_{2} \mathrm{X}_{3}+23.362 \mathrm{X}_{3}^{2}$

$\mathrm{Y}_{3}=-64.189+48.044 \mathrm{X}_{1}+0.031 \mathrm{X}_{2}+46.33 \mathrm{X}_{3}-4.519 \mathrm{X}_{1}^{2}-0.003$

$$
\mathrm{X}_{1} \mathrm{X}_{2}+0.645 \mathrm{X}_{1} \mathrm{X}_{3}+0.000002 \mathrm{X}_{2}^{2}-0.016 \mathrm{X}_{2} \mathrm{X}_{3}-10.385 \mathrm{X}^{2}
$$

The significance and magnitude of the studied dependent variables on the investigated responses was explained by Pareto charts (Figure 1). ANOVA test was used to test their significance. A positive sign indicates a synergistic effect while a negative sign indicates an antagonistic effect of the factor on the selected response.

\section{Effect on the particle size $\left(\mathrm{Y}_{1}\right)$}

The particle size distribution of $\mathrm{MBH}$-loaded chitosan microspheres is presented in Table 1. The mean particle size of the prepared microspheres
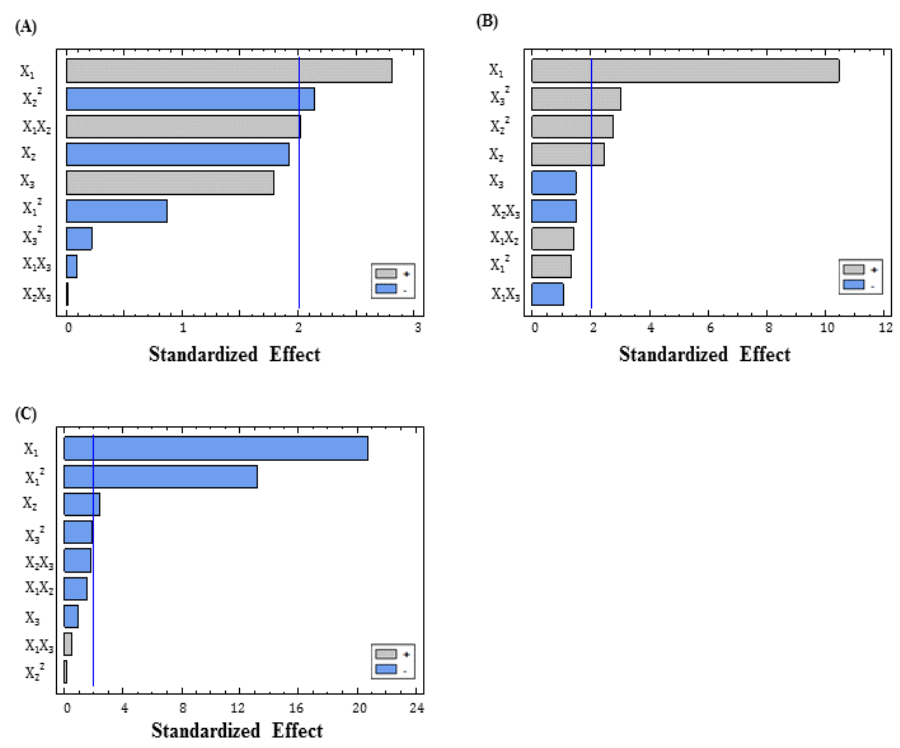

Figure 1: Standardized Pareto charts revealing the significance of the independent variables on the investigated dependent variables.Positive sign means synergistic effect while negative sign means antagonistic effect. was in the range of $32 \pm 0.45$ to $46.4 \pm 1.13 \mu \mathrm{m}$. It was obvious that both drug: polymer ratio $\left(\mathrm{X}_{1}\right)$ and the interaction effect $\mathrm{X}_{1} \mathrm{X}_{2}$ exerted a significant synergistic effect on the particle size $\left(\mathrm{Y}_{1}\right)$ of the prepared microspheres. On the other hand, neither the stirring speed $\left(\mathrm{X}_{2}\right)$ nor surfactant concentration $\left(\mathrm{X}_{3}\right)$ exerted any effect on the particle size $\left(\mathrm{Y}_{1}\right)$ as represented in Table 2 and Figure 1A. At the same levels of $\mathrm{X}_{2}$ and $\mathrm{X}_{3}$, increasing drug: polymer ratio $\left(\mathrm{X}_{1}\right)$ from $1: 4$ to $1: 8$ resulted in an increase in the average particle size of the formulated microspheres from $32 \pm 0.45 \mu \mathrm{m}$ (F2) to $40.7 \pm 1.53 \mu \mathrm{m}$ (F4), from $33 \pm 1.0 \mu \mathrm{m}$ (F5) to $41.3 \pm 0.57 \mu \mathrm{m}$ (F7) and from $38.6 \pm 0.51 \mu \mathrm{m}$ (F6) to $46.4 \pm 1.13 \mu \mathrm{m}$ (F8).

\section{Effect on drug entrapment $\left(Y_{2}\right)$}

The percentage entrapment efficiency of $\mathrm{MBH}$-loaded chitosan microspheres was in the range of $11.66 \pm 0.19 \%$ to $48.07 \pm 1.72 \%$ (Table 1 ). It was noticed that drug: polymer ratio $\left(\mathrm{X}_{1}\right)$ and stirring speed $\left(\mathrm{X}_{2}\right)$ exerted a significant synergistic effect on the percentage entrapment efficiency $\left(\mathrm{Y}_{2}\right)$ of the prepared microspheres. On the other hand, surfactant concentration $\left(\mathrm{X}_{3}\right)$ and the interaction effects $\left(\mathrm{X}_{1} \mathrm{X}_{2}\right),\left(\mathrm{X}_{1} \mathrm{X}_{3}\right)$ and $\left(\mathrm{X}_{2} \mathrm{X}_{3}\right)$ exerted insignificant effect on the percent drug entrapped $\left(\mathrm{Y}_{2}\right)$ as presented in Pareto chart (Figure 1B). Similarly, at the same levels of $\mathrm{X}_{1}$ and $\mathrm{X}_{3}$, stirring speed $\left(\mathrm{X}_{2}\right)$ exerted a positive effect on the percentage entrapment efficiency $\left(\mathrm{Y}_{2}\right)$.

\section{Effect on the cumulative percentage of drug release after $8 \mathrm{~h}\left(\mathrm{Y}_{3}\right)$}

The in vitro release of $\mathrm{MBH}$ from the prepared chitosan microspheres was conducted using buffer change method to mimic the GIT environment. As shown in Figure 2, the drug release for the initial $2 \mathrm{~h}$ in SGF ( $\mathrm{pH} 1.2)$ was found to be low in all formulations. Then, the drug release increased markedly (\% cumulative drug releaseranged from $57.36 \%$ to $100 \%$ at the end of $8 \mathrm{~h}$ ) depending on the level of factors in the formulations. In addition, it was noticed that both drug: polymer ratio $\left(\mathrm{X}_{1}\right)$ and stirring speed $\left(\mathrm{X}_{2}\right)$ possessed a significant antagonistic effect on the cumulative amount of $\mathrm{MBH}$ release after 8 hours $\left(\mathrm{Y}_{3}\right)$. On the other hand, surfactant concentration $\left(\mathrm{X}_{3}\right)$ failed to affect $\mathrm{MBH}$ release from chitosan microspheres at any of the studied concentrations $(p<0.05)$ (Table 2 and Figure 1C).
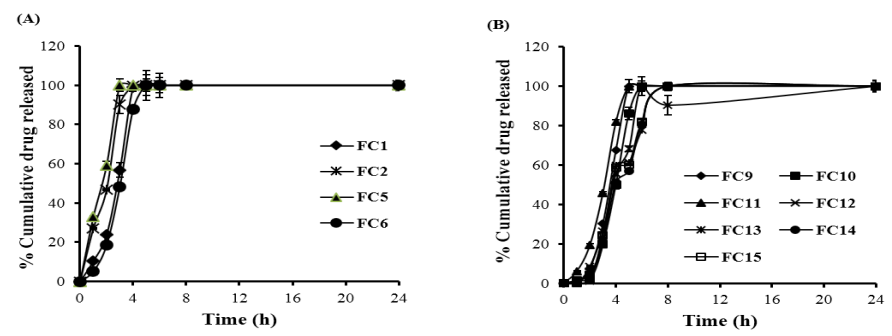

(C)

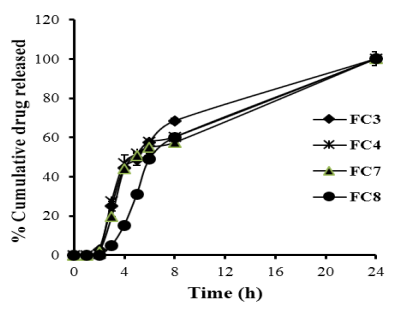

Figure 2: In vitro release profile of $\mathrm{MBH}$ from chitosan microspheres. Release of $\mathrm{MBH}$ from microspheres prepared with drug:polymer ratio (A) 1:4 (B) 1:6 (C) 1:8 at different stirring speed and different surfactant concentration. Data represents mean $\pm S D$. 
Table 2: Estimated effects of factors and associated $P$-values for dependent variables $\left(Y_{1}, Y_{2}\right.$ and $\left.Y_{3}\right)$.

\begin{tabular}{|c|c|c|c|c|c|c|}
\hline \multirow[t]{2}{*}{ Factor } & \multicolumn{2}{|c|}{$\mathrm{Y}_{1}$} & \multicolumn{2}{|c|}{$\mathrm{Y}_{2}$} & \multicolumn{2}{|c|}{$\mathrm{Y}_{3}$} \\
\hline & Factor effect & P-value & Factor effect & $P$-value & Factor effect & $P$-value \\
\hline $\mathrm{X}_{1}$ & 5.55 & $0.0374^{*}$ & 27.8325 & $0.0001^{*}$ & -38.5575 & $0.0000^{*}$ \\
\hline $\mathrm{X}_{2}$ & -3.8 & 0.1121 & 6.5225 & $0.0579^{*}$ & -4.4375 & $0.0622^{*}$ \\
\hline $\mathbf{X}_{3}$ & 3.55 & 0.1319 & -3.945 & 0.1984 & -1.755 & 0.3875 \\
\hline $\mathrm{X}_{1}^{2}$ & -2.525 & 0.4244 & 5.17583 & 0.2438 & -36.1575 & $0.0000^{*}$ \\
\hline $\mathrm{X}_{1} \mathrm{X}_{2}$ & 5.65 & $0.0988^{*}$ & 5.365 & 0.2134 & -4.075 & 0.1810 \\
\hline $\mathrm{X}_{1} \mathrm{X}_{3}$ & -0.25 & 0.9321 & -3.85 & 0.3534 & 1.29 & 0.6437 \\
\hline $\mathrm{X}_{2}^{2}$ & -6.225 & $0.0850^{*}$ & 10.8558 & $0.0393^{*}$ & 0.3925 & 0.8913 \\
\hline $\mathrm{X}_{2} \mathrm{X}_{3}$ & -0.05 & 0.9864 & -5.54 & 0.2011 & -4.8 & 0.1268 \\
\hline $\mathbf{X}_{3}^{2}$ & -0.625 & 0.8381 & 11.6808 & $0.0308^{*}$ & -5.1925 & 0.1156 \\
\hline \multicolumn{7}{|c|}{ Analysis of Variance } \\
\hline$R^{2}$ & 82.79 & & 96.53 & & 99.20 & \\
\hline $\operatorname{Adj.} R^{2}$ & 51.81 & & 90.28 & & 97.77 & \\
\hline SEE & 2.79 & & 3.76 & & 2.62 & \\
\hline MAE & 1.29 & & 1.88 & & 1.18 & \\
\hline
\end{tabular}

$\mathrm{X}_{1}$ is the polymer-drug ratio ; $\mathrm{X}_{2}$ is the stirring speed ; $\mathrm{X}_{3}$ is the surfactant concentration; $\mathrm{X}_{1} \mathrm{X}_{2}, \mathrm{X}_{1} \mathrm{X}_{3}, \mathrm{X}_{2} \mathrm{X}_{3}$ are the interaction terms between the factors; $\mathrm{X}_{1}^{2}, \mathrm{X}_{2}^{2}, \mathrm{X}_{3}^{2}$ are the quadratic terms of the factors; $Y_{1}$ is the particle size; $Y_{2}$ is the entrapment efficiency percentage; and $Y_{3}$ is the percentage of MB HCL cumulative release after 8 hrs. ${ }^{*}$ Significant effect of factors on individual responses.

\section{Selection of optimized Formula}

After analyzing the effect of selected variables on the targeted responses, the optimized formula for $\mathrm{MBH}$ were obtained at a drug: polymer ratio of 1:8, stirring speed of $1600 \mathrm{rpm}$ and surfactant concentration of $1 \% \mathrm{w} / \mathrm{v}$. The observed particle size, \% EE and \% drug release after $8 \mathrm{~h}$ of optimized formula were $40.55 \mu \mathrm{m}, 58.11 \%$ and $60.62 \%$, respectively, which were close to the predicted values $(38.88 \mu \mathrm{m}, 59.19 \%$ and $58.64 \%$, respectively) for the optimized formula. The optimized formula (FO) fulfilled the targets of the mathematical experimental design in having smaller particle size, optimum entrapment efficiency and controlled drug release in the colonic environment.

\section{Surface morphology of the optimized MBH-loaded microsphere formulation}

SEM studies of the optimized MBH-loaded chitosan microspheres (FO) indicate that the prepared microspheres exhibit a discrete spherical shape with nearly smooth surface (Figure 3 ).

\section{In vitro release study of optimized $\mathrm{MBH}$-loaded chitosan microspheres}

The in vitro release of $\mathrm{MBH}$ from the optimized formula (FO) was carried out in SGF ( $\mathrm{pH} 1.2$ ) and SIF ( $\mathrm{pH} 6.8$ and $\mathrm{pH} 7.4$ ) as abovementioned. The release of $\mathrm{MBH}$ from the optimized formula was slow with less than $35 \%$ drug released in both simulated gastric fluid and intestine fluid ( $\mathrm{pH}$ 6.8). However, a high amount of $\mathrm{MBH}(>65 \%)$ was released from optimized formula in colonic environment ( $\mathrm{pH} 7.4)$; emphasizing the applicability of our formulated chitosan microspheres for achieving site specific delivery to the colon.

\section{In vivo Pharmacokinetic study of optimized $\mathrm{MBH}$-loaded chitosan microsphere}

The in vivo pharmacokinetic of the optimized formula (FO) was evaluated and compared with that of free drug to address whether formulating
$\mathrm{MBH}$ within chitosan microspheres could improve drug systemic bioavailability (Figure 4). The mean pharmacokinetics parameters $\left(\mathrm{C}_{\max }, \mathrm{t}_{\max }, \mathrm{K}_{\mathrm{el}}, \mathrm{AUC}\right.$ and MRT) for optimized formula (FO) and free drug are summarized in Table 3. The optimized formula (FO) exhibited a higher peak plasma concentration compared to that of free drug $(168.51 \pm 20.05 \mathrm{ng} / \mathrm{ml}$ vs. $126.45 \pm 29.46 \mathrm{ng} / \mathrm{ml}$, respectively). In addition, the $t_{\max }$ for the optimized formula FO was significantly longer than that of free drug, indicating a delayed absorption of $\mathrm{MBH}$ from chitosan microspheres. Furthermore, the optimized formula showed higher area under the curve $\left(\mathrm{AUC}_{0-24}\right)$ than free drug $(1349.17 \pm 231.59 \mathrm{ng} / \mathrm{ml} . \mathrm{h}$ vs. $402.8744 \pm 89.88 \mathrm{ng} / \mathrm{ml} . \mathrm{h}$, respectively), reflecting higher extent of $\mathrm{MBH}$ absorption from chitosan microspheres.

\section{DISCUSSION}

Mebeverine hydrochloride ( $\mathrm{MBH})$ is an antispasmodic agent that is commonly used for the treatment of irritable bowel syndrome (IBS). ${ }^{4,5}$ Nevertheless, following oral administration, $\mathrm{MBH}$ is rapidly absorbed from the upper part of gastrointestinal tract and undergoes extensive first pass metabolism ${ }^{6}$ and thereby, shows a poor oral bioavailability. Accordingly, site specific delivery of $\mathrm{MBH}$ to the colon might represent a promising strategy for delivering $\mathrm{MBH}$ specifically in the colon in a reproducible and/or controlled manner. ${ }^{20,21}$

Nevertheless, for achieving colon targeting, the delivery vehicle should protect the drug from degradation, release and absorption in stomach and small intestine and should allow the selective/controlled release in the proximal colon. In the present study, therefore, $\mathrm{MBH}$ was loaded onto chitosan microspheres prepared with cross linking method using gluteraldehyde as a cross linking agent. Cross-linked chitosan is relatively stable in acidic medium but rapidly swell and gradually release its entrapped drug in an alkaline medium. ${ }^{22,23}$ Accordingly, by loading $\mathrm{MBH}$ onto cross-linked chitosan microspheres, only a little amount of $\mathrm{MBH}$ is expected to be released in the stomach. Whilst, at the intestinal $\mathrm{pH}$, the cross-linked chitosan will get swollen. This gelling property is anti- 


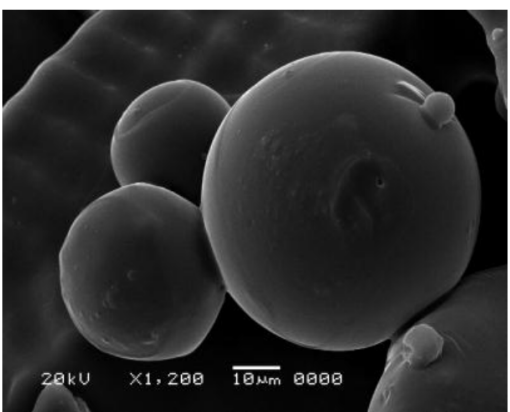

Figure 3: Scanning electron microscopy image of optimized MBH-loaded chitosan microsphere.

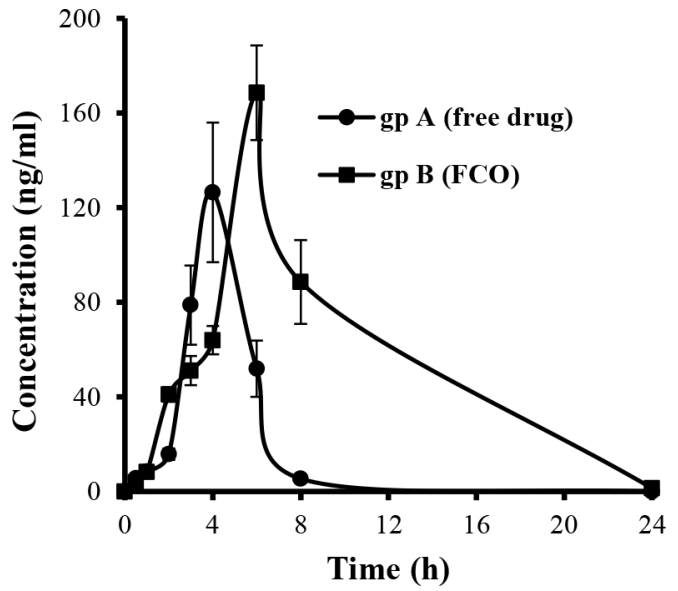

Figure 4: Mean plasma concentration-time profiles following oral administration of optimized formula (FCO) and free MBH.

Rabbits were orally treated with either free $\mathrm{MBH}$ or $\mathrm{MBH}$-loaded chitosan microspheres (FCO) at a dose of $20 \mathrm{mg} \mathrm{MBH} / \mathrm{kg}$. Data represent mean \pm SD $(n=4)$.

Table 3: Pharmacokinetics parameters after oral administration of different formulations of Mebeverine $\mathrm{HCl}$.

\begin{tabular}{ccc}
\hline \multirow{2}{*}{ Parameter } & \multicolumn{2}{c}{ Formula } \\
\cline { 2 - 3 } & FCO & Free drug \\
\hline $\mathrm{C}_{\max }(\mathrm{ng} / \mathrm{ml})$ & $168.51 \pm 20.05$ & $126.45 \pm 29.46$ \\
$\mathrm{~T}_{\max }(\mathrm{hr})$ & $6.00 \pm 0.002$ & $4.00 \pm 0.004$ \\
$\mathrm{~K}_{\mathrm{el}}\left(\mathrm{hr} \mathrm{r}^{-1}\right)$ & $0.29 \pm 0.08$ & $0.79 \pm 0.02$ \\
$\mathrm{AUC}_{0-24}(\mathrm{ng} / \mathrm{ml} . \mathrm{hr})$ & $1343.40 \pm 226.11$ & $402.8744 \pm 89.88$ \\
$\mathrm{AUC}_{0-\infty}(\mathrm{ng} / \mathrm{ml} . \mathrm{hr})$ & $1349.17 \pm 231.59$ & $409.86 \pm 92.14$ \\
$\mathrm{MRT}(\mathrm{hr})$ & $6.99 \pm 0.26$ & $4.31 \pm 0.02$ \\
\hline
\end{tabular}

Data represent mean \pm S.D $(n=4)$.

cipated to retard $\mathrm{MBH}$ release in the small intestine until reach the site of action (colon).

A three-level Box-Behnken design was employed to optimize the formulation parameters of $\mathrm{MBH}$ microspheres for maximum entrapment percent, optimum particle size and controlled percent drug release. Increasing drug: polymer ratio from 1:4 to 1:8 resulted in an increase in the average particle size of the formulated microspheres (Table 1). These findings might be attributed to the increment in the viscosity of the dispersed phase upon increasing polymer concentration, which in turn, favors the formation of larger droplets and consequently larger microspheres. ${ }^{24}$ Similarly, increasing drug: polymer ratio exerted a synergistic effect on entrapment efficiency percentage (Figure 1). Such synergistic effect was ascribed to the increase in aqueous phase viscosity of aqueous phase upon increasing polymer concentration, which in turn, stabilize droplets and inhibit the leakage of drug during the hardening phase. ${ }^{25}$ On the other hand, drug: polymer ratio was found to exert an antagonistic effect on percentage drug released after $8 \mathrm{~h}$ (Figure 1). Such antagonistic effect might be attributed, on the one hand, to the fact that increasing polymer concentration increases the density of polymer matrix and triggers the formation a thicker matrix wall of microspheres with less number of pores, which in turn, results in the prolongation of diffusion path for the drug and thereby hindering drug release from microspheres. On the other hand, at higher drug: polymer ratio (1:8), the number of $\mathrm{NH}_{2}$ groups of chitosan available for cross-linking with - COO group of glutaraldehyde will be much higher than those at lower drug: polymer ratios (1:4 or 1:6), which favors more cross-linking reaction. Increasing cross-linking density is reported to increase the hydrophobicity of chitosan matrix and prolong the time for hydration resulting in lower and/or controlled drug release from microspheres. ${ }^{26}$

Site specific drug delivery to the colon has recently gained increased attention as a mean for delivering drugs specifically in the colon in a reproducible and/or controlled manner. ${ }^{7-9}$ In this study, the feasibility of cross-linked chitosan microspheres as a vehicle for $\mathrm{MBH}$ site specific delivery to the colon was investigated. In vitro release study of optimized formula revealed a controlled site specific delivery of the majority of entrapped drug at the colonic environment. In addition, in vivo evaluation of optimized $\mathrm{MBH}$-loaded chitosan microspheres proved that entrapment of $\mathrm{MBH}$ within chitosan microspheres significantly enhances drug oral bioavailability compare to free counterpart (Figure 4 and Table 3 ). The bioavailability of $\mathrm{MBH}$ from the optimized formula $(\mathrm{FO})$ was $\approx 3$ times greater than that of free drug. These results underscore the potential use of $\mathrm{MBH}$-loaded chitosan microspheres for treating diseases associated with the colon such as irritable bowel syndrome.

\section{CONCLUSION}

In the present study, MBH-loaded chitosan microspheres were prepared, optimized and evaluated for their effectiveness for achieving site specific delivery of $\mathrm{MBH}$ to the colon. In vitro release studies verified the sitespecific drug release at the colonic environment; with more than $60 \%$ of entrapped drug released at the colon. In addition, pharmacokinetic studies confirmed the highest rate and extent of drug absorption from the optimized formula, compared to free drug, leading to a significant enhancement in drug bioavailability. Collectively, $\mathrm{MBH}$-loaded chitosan microspheres might represent a potential alternative for conventional oral dosage forms for treating diseases associated with the colon such as irritable bowel syndrome.

\section{ACKNOWLEDGEMENT}

The authors want to thank The Egyptian International Pharmaceuticals Industries Company for granting samples of mebrverine hydrochloride.

\section{CONFLICT OF INTEREST}

The authors report no conflicts of interest in this work.

\section{ABBREVIATIONS USED}

IBS: Irritable bowel syndrome; MBH: Mebeverine hydrochloride; EE: Entrapment efficiency; SGF: simulated gastric fluid; SIF: simulated intestinal fluid; $\mathbf{C}_{\max }:$ Peak plasma concentration; $\mathbf{t}_{\max }$ : Time of maximum 
concentration; Kel: Elimination rate constant; AUC: Area under the curve; MRT: Mean residence time; SEM: Scanning electron microscope.

\section{REFERENCES}

1. Jones R, Lydeard S. Irritable bowel syndrome in the general population. BMJ. 1992;304(6819):87-90.

2. Mayer EA. Clinical practice. Irritable bowel syndrome. $\mathrm{N}$ Engl J Med. 2008;358(16):1692-9.

3. Arayne MS, Sultana N, Siddiqui FA. A new RP-HPLC method for analysis of mebeverine hydrochloride in raw materials and tablets. Pak J Pharm Sci. 2005:18(2):11-4.

4. Evans PR, Bak YT, Kellow JE. Mebeverine alters small bowel motility in irritable bowel syndrome. Aliment Pharmacol Ther. 1996;10(5):787-93.

5. Gilbody JS, Fletcher CP, Hughes IW, Kidman SP. Comparison of two different formulations of mebeverine hydrochloride in irritable bowel syndrome. Int J ClinPract. 2000;54(7):461-4.

6. Dickinson RG, Baker PV, Franklin ME, HooperWD. Facile hydrolysis of mebeverine in vitro and in vivo: Negligible circulating concentrations of the drug after oral administration. J Pharm Sci. 1991;80(10):952-7.

7. Chourasia MK, Jain SK. Pharmaceutical approaches to colon targeted drug delivery systems. J Pharm Pharm Sci. 2003;6(1):33-66.

8. Tiwari G, Tiwari R, Sriwastawa B, Bhati L, Pandey S, Pandey P, et al. Drug delivery systems: An updated review. Int J Pharm Investig. 2012;2(1):2-11.

9. Yang L, Chu JS, Fix JA. Colon-specific drug delivery: New approaches and in vitro/in vivo evaluation. Int J Pharm. 2002;235(1-2):1-15.

10. Lennard-Jones JE. Classification of inflammatory bowel disease. Scand J Gastroenterol Suppl. 1989;170:2-6.

11. Pantel K, Deneve E, Nocca D, Coffy A, Vendrell JP, Maudelonde T, et al. Circulating epithelial cells in patients with benign colon diseases. Clin Chem. 2012;58(5):936-40

12. Mura C, Nacher A, Merino V, Merino-Sanjuan M, Manconi M, Loy G, et al. Design, characterization and in vitro evaluation of 5-aminosalicylic acid loaded $\mathrm{N}$-succinyl-chitosan microparticles for colon specific delivery. Colloids Surf B Biointerfaces. 2012;94:199-205.

13. Perera G, Barthelmes J, Bernkop-Schnurch A. Novel pectin-4-aminothiophenole conjugate microparticles for colon-specific drug delivery. J Control Release. 2010;145(3):240-6

14. Aguero L, Zaldivar-Silva D, Pena L, Dias ML. Alginate microparticles as oral colon drug delivery device: A review. Carbohydr Polym. 2017;168:32-43.

15. Mladenovska K, Raicki RS, Janevik El, Ristoski T, Pavlova MJ, Kavrakovski Z, et al. Colon-specific delivery of 5-aminosalicylic acid from chitosan-Ca-alginate microparticles. Int J Pharm. 2007;342(1-2):124-36.

16. Abdou ES, Nagy KS, Elsabee MZ. Extraction and characterization of chitin and chitosan from local sources. Bioresour Technol. 2008;99(5):1359-67.

17. George M, Abraham TE. Polyionic hydrocolloids for the intestinal delivery of protein drugs: alginate and chitosan: A review. J Control Release. 2006;114(1):1-14

18. Rajpurohit H, Sharma P, Sharma S, Bhandari A. Polymers for colon targeted drug delivery. Indian J Pharm Sci. 2010;72(6):689-96.

19. Thanoo BC, Sunny MC, Jayakrishnan A. Cross-linked chitosan microspheres: preparation and evaluation as a matrix for the controlled release of pharmaceuticals. J Pharm Pharmacol. 1992;44(4):283-6.

20. Amidon S, Brown JE, Dave VS. Colon-targeted oral drug delivery systems: Design trends and approaches. AAPS Pharm Sci Tech. 2015;16(4):731-41.

21. Philip AK, Philip B. Colon targeted drug delivery systems: A review on primary and novel approaches. Oman Med J. 2010;25(2):79-87.

22. Berthold A, Cremer K, Kreuter J. Preparation and characterization of chitosan microspheres as drug carrier for prednisolone sodium phosphate as model for anti-inflammatory drugs. Journal of Controlled Release. 1996;39(1):17-25.

23. Vasir JK, Tambwekar K, Garg S. Bioadhesive microspheres as a controlled drug delivery system. Int J Pharm. 2003;255(1-2):13-32.

24. Fu X, Ping $Q$, Gao Y. Effects of formulation factors on encapsulation efficiency and release behaviour in vitro of huperzine A-PLGA microspheres. J Microencapsul. 2005;22(1):57-66

25. Patel KS, Patel MB. Preparation and evaluation of chitosan microspheres containing nicorandil. Int J Pharm Investig. 2014;4(1):32-7.

26. Ahmadi F, Oveisi Z, Samani SM, Amoozgar Z. Chitosan based hydrogels: characteristics and pharmaceutical applications. Res Pharm Sci. 2015;10(1):116.

27. Tummala S, Satish Kumar MN, Prakash A. Formulation and characterization of 5-Fluorouracil enteric coated nanoparticles for sustained and localized release in treating colorectal cancer. Saudi Pharm J. 2015;23(3):308-14.

Article History: Submission Date : 03-04-2020; Revised Date : 30-04-2020; Acceptance Date : 10-05-2020

Cite this article: Hasan AA, Samir RM, Abu-Zaid SS, Abu Lila AS. Mebeverine Hydrochloride Loaded Chitosan Microspheres as Potential Treatment Targeting Irritable Bowel Syndrome: Box-Behnken Design Optimization. Int.J. Pharm. Investigation. 2020;10(3):326-31. 